\title{
INSTRUCTIONS FOR AUTHORS
}

Editorial communications and manuscripts should be sent to: Navin C. Nanda, M.D., University of Alabama at Birmingham, Heart Station, SW-S102, 619 19th Street South, Birmingham AL 35249-6846. Fax number: (205) 934-6747; E-mail: lindy@cardio.dom.uab.com.

For subscription requests, reprint orders, and other business communications contact: Blackwell Futura Publishing, Inc., 350 Main St., Malden, MA. Fax: 914-273-1016, e-mail: jrlinfo@futuraco.com

Manuscripts submitted to Echocardiography: A Journal of Cardiovascular Ultrasound and Allied Techniques must not be under simultaneous consideration by any other publication and should not have been published elsewhere in substantially similar form. No part of a paper that has been published by Echocardiography: A Journal of Cardiovascular Ultrasound and Allied Techniques may be reproduced or published elsewhere without the written permission of the author(s) and the publisher.

Echocardiography: A Journal of Cardiovascular Ultrasound and Allied Techniques publishes peer-reviewed articles dealing with all aspects of cardiovascular ultrasound and allied techniques.

\section{Manuscript Preparation}

Manuscripts must be submitted in English in triplicate (one original and two copies) and typed double-spaced on $22 \mathrm{~cm} . \times 29 \mathrm{~cm} .\left(8 \frac{1}{1} / 2 \mathrm{in} . \times 11\right.$ in.) white bond paper. This applies to all parts of the manuscript, i.e., references, legends, etc. Liberal margins should be left at the top and bottom, as well as the sides. The manuscript should be submitted in the following order: Title Page, Abstract, Text, References, Tables, and Legends. Each page, beginning with the Abstract, should include the senior author's surname and page number typed in the upper, righthand corner. Authors are encouraged to submit computer diskettes with the final revised versions of their manuscripts. All material should be submitted in a run-in style (do not use double columns). All print commands (e.g. superscript, subscript, italics) should be included on the disk and should also appear on the hardcopy printout. Submit the diskette with a label clearly indicating the journal name, author's name, manuscript title, hardware (IBM or Mac) and software used (word processing program), and name of text file.

Computer-generated artwork supplied on diskette will be output electronically, whenever possible. EPS and TIFF files capable of being sized are preferred. Please submit figures on a separate diskette specifying the hardware and software (name and version) used. Hard copy of all art should be supplied. Please contact publisher should you require detailed information for preparing digital art.

An excellent reference is A SPECIAL REPORT: UNIFORM REQUIREMENTS FOR MANUSCRIPTS SUBMITTED TO BIOMEDICAL JOURNALS. N Engl J Med 1997; 3336:309-315 and Ann Intern Med 1997; 126:36-47. Where uniform requirements differ; the Echocardiography instructions prevail. The AMA Style Manual is a useful reference.

Title Page

—Include full name(s), highest academic degree(s), and affiliation(s) of author(s); list under title. If two authors contributed equally to the manuscript, the two authors should be listed as first and second authors and a note placed on the title page of the submitted manuscript. Upon publication, a footnote will be added at the bottom of the first page as follows: "The first 2 authors contributed equally to this work".

- Give a shortened title of 3 to 6 words.

-At the bottom of the page, include information about grants, if applicable. —Add: "Address for correspondence and reprints: ...," followed by full name, address, e-mail, and telephone and fax numbers.

\section{Abstract}

-Abstract should be after title page and numbered page 1 .

- It should not exceed 250 words for major articles; case reports should have abstracts of no more than 100 words.

-At the end of the abstract, provide a maximum of 6 key words suitable for indexing.

Text

-The text should begin on a new page, as should References, Tables, and Legends.

- Metric, Sl units, and Celsius measurements should be used throughout. -Abbreviations should be explained when they first appear in the text.

-References should be cited in numerical order, as should tables and figures. Personal Communications (written) may be used as references; unpublished data may not be used.

\section{References}

-Number in the order in which they appear in the text.

-Abbreviate titles of periodicals according to the style of the Index Medicus.

-Follow the format (arrangement, punctuation, inclusive pages) shown below:

\section{Periodicals}

1. Sadaniantz A, Burtt D, Nanda N, et al: Three-Dimensional Echocardiography of Right Heart Pathology. Echocardiography 1998:15:795-806. (if more than three authors, please use "et al")
Books

(edited by other than author of article)

2. Myerberg RJ, Mitrani R, Interain A, et al: Identification of Risk of Cardiac Arrest and Sudden Death in Athletes. In Estes NAM, Salem DM, Wang PJ (eds): Sudden Cardiac Death in the Athlete. Blackwell Futura Publishing, Inc., Armonk, 1999, p. 25-27.

\section{Books}

(identical author and editor)

3. Kerut K, Mcllwain EF, Plotnick GD: Handbook of Echo-Doppler Interpretation, Futura Publishing Co., Inc., Armonk, NY 1996, p. 137.

\section{Personal Communications}

4. Smith I: personal communication, December 10, 1976.

Abstracts

5. Same as periodicals and followed by "(Abstract)."

Tables

- Tables should supplement, but not duplicate, the text.

- Tables should be numbered consecutively in order of appearance in the text.

-Each table must be given a Roman numeral and a title, placed at the top of the page.

-Abbreviations used in the table should be footnoted and explained in the order in which they appear in the table, if they have not been used previously.

-Any material that is not self-explanatory should be footnoted as well. Legends

- Be sure that legends and figures correspond.

- Identify all abbreviations used in a figure at the end of each legend in alphabetical order.

Figures

-Submit either 3 glossy prints or 2 prints and one photocopy of $13 \mathrm{~cm}$. $\times$ $18 \mathrm{~cm}$. (5 in. $\times 7$ in.) size.

-On the back of each figure, indicate number, senior author's surname, top of illustration; all of this should be written lightly with soft, black pencil.

-For color photographs, submit original slides and two sets of hardcopy figures or three total sets of hardcopy figures.

- Submit written permission from publisher(s) for any figure that has been published previously.

-Do not use clips on illustrations; submit them in an envelope backed by cardboard.

-Any lettering or scale of measurement used in an illustration must be large enough to be legible in the event of half-size reduction.

-Do not send original art-work, X-rays, or ECGs.

- Photographs in which a patient or other person is identifiable must have written permission from that person. The consent must state specifically what the person is consenting to and what restrictions, if any, the person has placed upon the publication of the photograph. All restrictions must be strictly observed.

Special arrangements for color illustrations must be made with the publisher at a cost of $\$ 375$ per page (one side).

Image Section. Manuscripts should be typed double spaced and no longer than 1 typed page of text (no abstract), a maximum of 4 figures and figure legends, and no more than 4 references. In addition to the case report, the manuscript should include the clinical or echocardiographic importance of the particular case and mention of previous reports, if any, on the particular topic.

The author is responsible for all material presented in a paper. The journal disclaims all responsibility for such material. No product or service advertised in this publication is guaranteed or warrantied either by the editors or the publisher. Neither the editors nor publisher guarantee any claims made by a manufacturer or an author in regard to a product or service. If a trademark item is named, the name(s) and address(es) of the manufacturer(s) or supplier(s), in addition to the generic product name, should be supplied. 